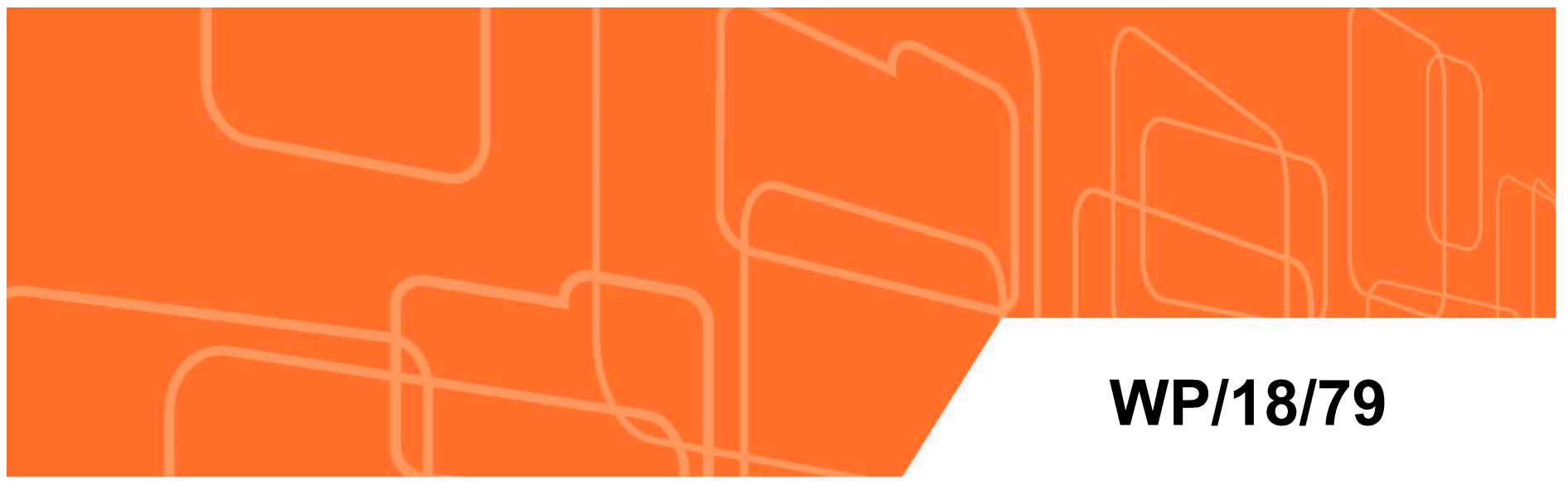

IMF Working Paper

\title{
The Stabilizing Role of Net Foreign Asset Returns
}

by Gustavo Adler and Daniel Garcia-Macia

IMF Working Papers describe research in progress by the author(s) and are published to elicit comments and to encourage debate. The views expressed in IMF Working Papers are those of the author(s) and do not necessarily represent the views of the IMF, its Executive Board, or IMF management.

$$
\text { I N T E R N A T I O N A L M O N E T A R Y F U N D }
$$




\title{
IMF Working Paper
}

\author{
Research Department
}

\section{The Stabilizing Role of Net Foreign Asset Returns* \\ Prepared by Gustavo Adler and Daniel Garcia-Macia}

Authorized for distribution by Luis Cubeddu

March 2018

\section{IMF Working Papers describe research in progress by the author(s) and are published to elicit comments and to encourage debate. The views expressed in IMF Working Papers are those of the author(s) and do not necessarily represent the views of the IMF, its Executive Board, or IMF management.}

\begin{abstract}
With the rapid growth of countries' foreign asset and liability positions over the last two decades, financial returns on those positions ('NFA returns') have become material drivers of current accounts and net stock positions. This paper documents the relative importance of NFA return versus trade channels in driving NFA dynamics, for a sample of 52 economies over 1990-2015. While persistent trade imbalances have been a strong force leading to diverging NFA positions, NFA returns have played an important stabilizing role, mitigating NFA divergence. The stabilizing role of NFA returns primarily reflects the response of asset prices, rather than yield differentials or exchange rates. There is also evidence of heterogeneity in the speed of NFA adjustment, with emerging market economies adjusting more rapidly than advanced economies, and reserve-currency countries adjusting more slowly than others. The paper also documents the role of NFA returns as insurance against domestic and global income shocks, with a focus on reserve-currency countries.
\end{abstract}

JEL Classification Numbers: F36, G12, F32

Keywords: net foreign assets, international investment position, valuation changes, return differential.

Author's E-Mail Address: gadler@imf.org; dgarciamacia@imf.org

\footnotetext{
*The paper benefited from comments and feedback from Luis Cubeddu, Thomas Elkjaer, Pierre-Olivier Gourinchas, Manos Kitsios, Signe Krogstrup, Bernardo Lischinsky, Yun Liu, Gian-Maria Milesi-Ferretti, Jose Manuel Montero, Maurice Obstfeld, Jonathan Ostry and Anne-Charlotte Paret-Onorato. Hongrui Zhang provided excellent research assistance.
} 


\section{Introduction}

The world economy has grown increasingly integrated over the last two decades, both in terms of trade and financial linkages. Particularly striking was the rapid expansion of gross foreign asset and liability positions, especially in the 1990's and early 2000's, which led to a tripling of such positions, from about 60 percent of world GDP in the early 1990's to about 160 percent in recent years (Figure 1). In many cases, expanding gross stock positions were accompanied by widening net positions, as large creditor countries ran current account surpluses for much of this period, mirrored by current account deficits in debtor countries. ${ }^{1}$

With growing gross and net foreign assets (NFAs), questions have arisen about external sustainability in systemic economies and globally, the drivers of external positions, and the role played by different stabilizing mechanisms. Policymakers and academics have paid increased attention to the role of yield differentials and valuation changes on NFAs, as they appear to have gained importance relative to traditional adjustment through the trade balance, in part as a direct consequence of the larger gross stock positions (Figure 2). Financial returns on NFAs have been the focus of attention in some prominent cases, like Japan, where the income balance has been the main driver of the overall current account balance in recent years; or China and Switzerland, where NFA valuation changes appear to have played an important role in stabilizing NFA positions, by offsetting the accumulation of external wealth via current account surplus balances. ${ }^{2}$

Understanding the relative importance of the financial return and trade channels is paramount to understanding the process of external adjustment, and assessing the sustainability and risks of countries' external positions. ${ }^{3}$ Yet, the understanding of such process of adjustment remains limited.

This paper sheds some light on this issue by documenting the patterns of NFA dynamics for a sample of 52 economies over the period 1990-2015, within a conceptual framework that allows to analyze the key mechanisms of NFA adjustment, including the role of financial returns on stock positions ("NFA returns").

We find that global NFA positions (in absolute values) have grown over the last two decades driven by persistent trade imbalances, which have shown no sign of adjusting in response to growing NFA positions. More importantly, there is evidence that NFA returns have played an important stabilizing role. That is, the stabilizing process of NFA positions

\footnotetext{
${ }^{1}$ See related discussion in the IMF External Sector Report (International Monetary Fund (2016) and International Monetary Fund (2017a)).

${ }^{2}$ See, for example, Darvas and Hüttl (2017) and Tille (2017).

${ }^{3}$ It can also shed light on the potential costs of mercantilistic policies, which may increase trade balances, but at the expense of experiencing offsetting low financial returns, as discussed further below.
} 
Figure 1: Global financial integration

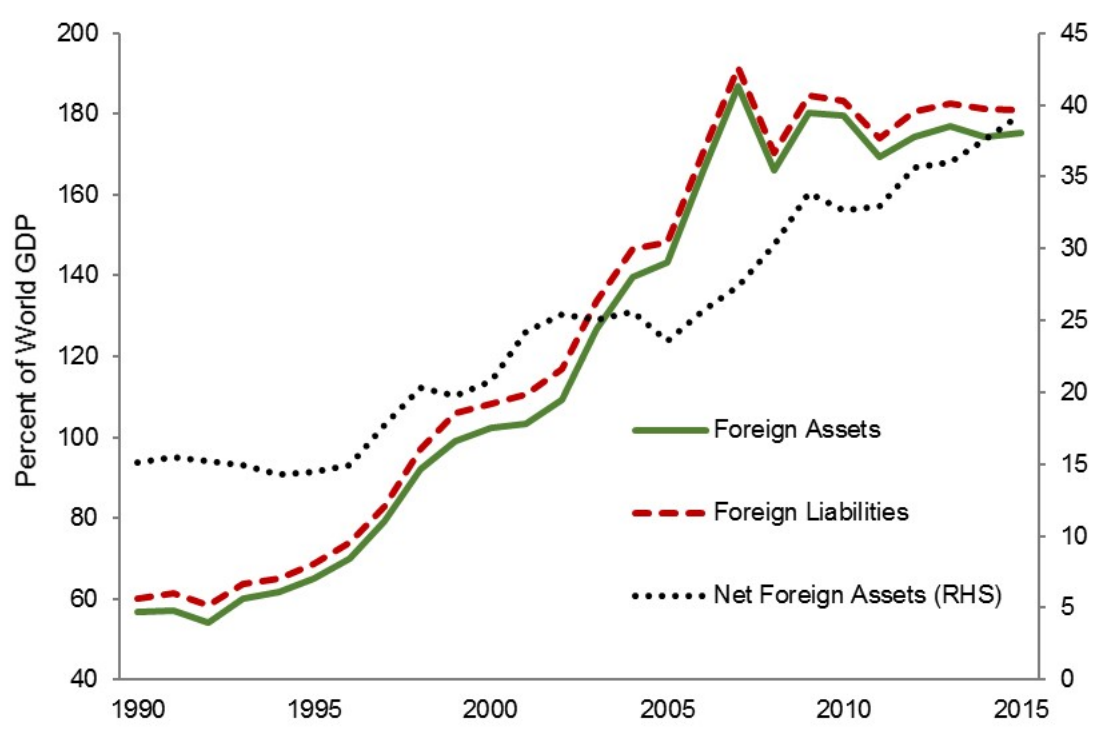

Notes: NFA are expressed in absolute value. Data from Lane and Milesi-Ferretti database (2017).

Figure 2: Trade balances and real NFA returns

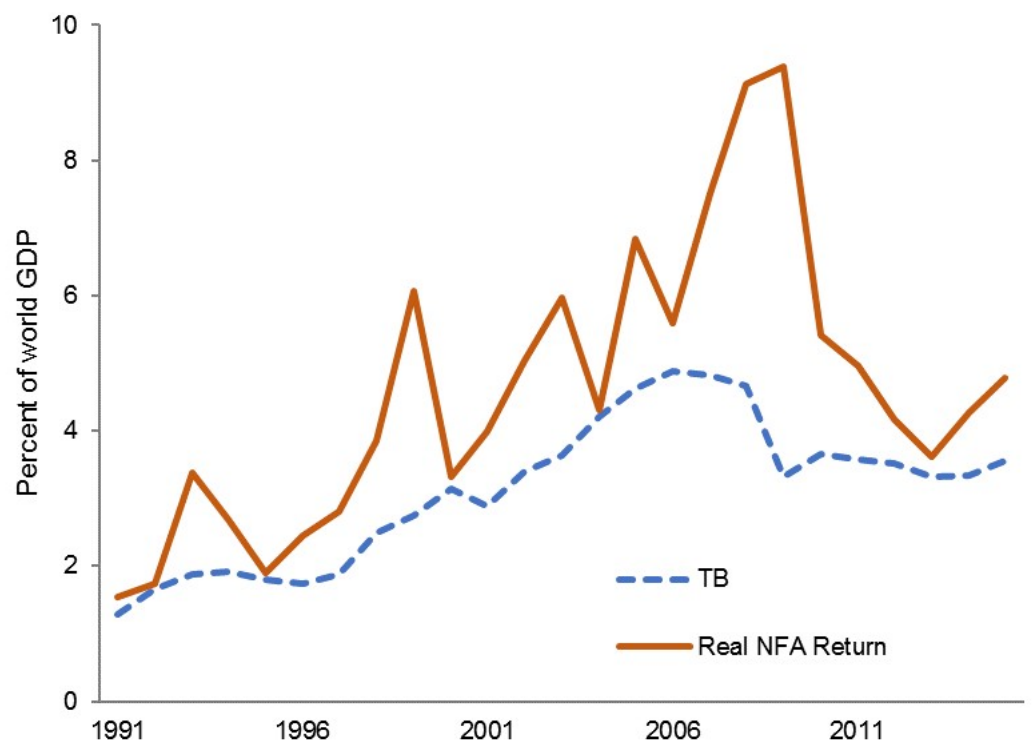

Notes: Average absolute value across countries is reported.

NFA return is defined as income balance plus NFA valuation changes minus an inflation component, in percent of GDP. Data from Lane and Milesi-Ferretti database (2017). 
of countries with greater external wealth has not entailed running lower trade balances, and vice versa. Instead, adjustment has taken place primarily through counterbalancing NFA returns. Specifically, we find that, on average, a 10 percent of GDP higher NFA has been associated with a 0.6 percent of GDP lower (annual) NFA return within a country. This stabilizing effect of NFA returns appears to have taken place mainly through asset prices (of a country's liabilities, in particular), pointing to the role of domestic stock prices in driving the adjustment.

Exploring cross-country heterogeneity, we find that the speed of NFA adjustment (mean reversion process) is significantly higher for emerging market economies (EMEs) than for advanced economies (AEs). Interestingly, this is the case not only for debtor EMEs, where tighter credit constraints may lead to more rapid adjustment, but also for creditor EMEs. At the same time, on average, countries that issue global reserve currencies are found to adjust at a significantly slower pace than other countries. This is not only the case for the US but also for other issuers of reserve currencies.

The paper also explores the role of NFA returns as insurance against domestic and global income shocks. We find evidence that NFA returns effectively act as insurance for domestic shocks, in macro-economically meaningful magnitudes. Specifically, a 1 percent drop in GDP growth, on average, is associated with a positive NFA return of about 0.6 percent of GDP. While magnitudes vary across countries, this insurance role of NFA returns is found to be a broad phenomenon. The associated transfer of wealth appears to take place mainly through asset price changes (e.g., negative income shocks leading to lower stock prices, thus, reducing the value of foreign equity liabilities); and to a lesser extent through exchange rate movements (e.g., the domestic currency depreciates with a negative income shock, reducing the value of both foreign equity and debt liabilities). Finally, and in line with previous findings for the US (e.g. Gourinchas et al. (2010)), we find that most reserve-currency countries are providers of insurance against global income shocks in a scale broadly commensurate to the size of their economies.

Our paper takes forward the seminal empirical work of Gourinchas and Rey (2007) and more recent work by Curcuru et al. (2013)-who focused primarily on the US- by extending their analysis to a larger set of economies, including both AEs and EMEs. Other related work includes Forbes et al. (2017), who document how the structure of NFAs affects aggregate NFA returns for 10 OECD countries and the implications for external sector vulnerability; Alberola et al. (2017) who explore the relationship between NFA and the current account; and Darvas and Hüttl (2017), who delve into how returns on foreign assets and liabilities help to stabilize NFA positions.

Relative to these studies, our work presents a broader sample coverage and, more impor- 
tantly, explores the different stabilizing mechanisms of NFA dynamics, disentangling external adjustment through trade versus NFA returns. This contrasts with previous studies which have focused on the current account as a whole, thus combining the trade channel with some components of the NFA return channel (yield), which makes the interpretation of the adjustment mechanisms more difficult. Our work also provides a decomposition of return differentials into yields, asset price valuation changes and exchange rate valuation changes to study their individual roles in the adjustment process. Finally, this paper documents the insurance role of NFA returns for a broad set of countries, and the global insurer role of reserve-currency issuers beyond the US.

From a theoretical perspective, our paper relates to the modeling work by Obstfeld and Rogoff (2005), Tille (2008), Devereux and Sutherland (2010), Pavlova and Rigobon (2010), Nguyen (2011) and Ghironi et al. (2015), which studies the role of IIP valuation changes as an external adjustment mechanism.

The rest of the paper is organized as follows. Section 2 presents key definitions and accounting identities to frame the discussion on adjustment channels. Sections 3 and 4 describe the data and present key stylized facts, respectively. Section 5 presents the econometric approach to test the importance of the different NFA-stabilizing channels. Section 6 explores the insurance role of NFA returns. Section 7 concludes with a summary of the paper's findings and a discussion of avenues for future research.

\section{Accounting Identities and Estimation}

We begin by defining key concepts for the analysis of NFA dynamics and the different adjustment mechanisms.

A country's nominal net foreign asset $(N F A)$ position equals foreign assets $(A)$ minus foreign liabilities $(L)$. Its (annual) change can be decomposed as: ${ }^{4}$

$$
N F A_{t}-N F A_{t-1}=F A_{t}+V_{t}+\varepsilon_{t}
$$

where $F A$ denotes the net flow of transactions (in assets and liabilities) as recorded in the financial account of the balance of payments, $V_{t}$ denotes NFA valuation changes and $\varepsilon_{t}$ is a reconciliation residual between flow and stock positions, which can be related to statistical updates in stocks data or debt default (see further discussion below).

From the balance of payments (BOP) identity, the financial account can be defined as:

\footnotetext{
${ }^{4}$ Throughout the paper, the terms net foreign asset (NFA) and international investment position (IIP) are used indistinctly.
} 


$$
F A_{t}=\underbrace{T B_{t}+I B_{t}}_{\text {current account }}+K A_{t}+E O_{t}
$$

where $T B$ is the trade balance, $I B$ is the income balance, $K A$ is the capital account and $E O$ are errors and omissions. The first two terms constitute the current account. ${ }^{5}$

Throughout the paper, the reconciliation residual $\varepsilon$ is assumed to be zero on average, following the ("residual") approach of Gourinchas and Rey (2007) and International Monetary Fund (2017a). ${ }^{6}$ Hence, we can estimate NFA valuation changes as:

$$
V_{t}=\left(N F A_{t}-N F A_{t-1}\right)-F A_{t}
$$

Similarly, valuation changes on gross assets $\left(V_{t}^{A}\right)$ can be estimated as the residual between the change in the total asset position and net asset purchases $\left(F A_{t}^{A}\right)$ :

$$
V_{t}^{A}=\left(A_{t}-A_{t-1}\right)-F A_{t}^{A}
$$

and a symmetric formula applies to valuation changes on liabilities $V_{t}^{L}$. Hence, $V_{t}=V_{t}^{A}-$ $V_{t}^{L} \cdot{ }^{7}$ All level variables throughout the paper are denominated in current US dollars, unless otherwise indicated. ${ }^{8}$

We define the nominal NFA return as:

$$
N R_{t}^{N F A} \equiv I B_{t}+V_{t}
$$

which encompasses the income balance and valuation change components. ${ }^{9}$

This treatment of different components of the current account allows us to properly

\footnotetext{
${ }^{5} \mathrm{~A}$ further refinement entails disaggregating the income balance into investment and other income. In most cases, investment income is the largest component of the income balance.

${ }^{6} \mathrm{~A}$ few countries (about one sixth of our overall sample of country-years) provided data, on a confidential basis, on the decomposition of valuation changes into different components, including the reconciliation residual. For most countries within this reduced sample, average reconciliation residuals are not statistically different from zero.

${ }^{7}$ An alternative ("direct") approach for estimating valuation changes with data on IIP structure and prices is also feasible for a few countries. This entails using information on the currency and security structure of assets and liabilities, along with proxies of key prices (e.g., debt, stocks and exchange rates) in order to estimate valuation changes by type of securities and sum them to obtain an aggregate measure of valuation changes. See Curcuru et al. (2013) for a comparison of the residual and direct approaches for the US. The paper build on the residual approach as data on these components are scarce for most countries.

${ }^{8}$ Valuation changes and financial returns more broadly can be computed in US dollars or in local currency. While these two measures can differ considerably in nominal terms, differences are small in real terms. The paper's main results are robust to using either approach (see Appendix A.2).

${ }^{9}$ Throughout the paper, 'income balance' refers to net investment income. Other components of the income balance (secondary income and non-investment primary income) are normally small.
} 
differentiate the role of the trade balance (which can be interpreted as a choice variable) from the financial returns on assets and liabilities (which are determined by the existing portfolio structure). This contrasts with previous work (e.g. Alberola et al. (2017)) which focused on the current account as a whole, entangling the trade channel with part, but not all, of the financial return channel. Another advantage of the above measure of overall financial return is that it is less affected by differences in the type of return of debt and equity assets. That is, the largest share of the return on debt securities is captured in the income balance, while the largest share of the return on equity is captured in valuation changes. The above definition of NFA return makes this distinction-which is not economically meaningful-irrelevant. Finally, an important reason for focusing on total financial returns relates to the treatment of retained earnings on equity portfolio positions under BOP statistics, as these are not recorded as income on the current account, thus leading to systematic NFA valuation changes in some cases.

The dynamic equation for NFA (1) can therefore be written as:

$$
N F A_{t}=N F A_{t-1}+T B_{t}+K A_{t}+E O_{t}+N R_{t}^{N F A}
$$

Further, expressing all variables as share of GDP (e.g. nfat $\equiv \frac{N F A_{t}}{G D P_{t}}$ ) for comparability across countries and time, and considering that $K A_{t}$ and $E O_{t}$ tend to be small in relation to other NFA drivers, the change in the $n f a_{t}$ can be decomposed as ${ }^{10}$

$$
\Delta \mathrm{nfa}_{t} \approx t b_{t}+r^{N F A}+g^{N F A}
$$

where

$$
\begin{aligned}
r^{N F A} & \equiv n r_{t}^{N F A}-\frac{\pi_{t} \mathrm{nfa}_{t-1}}{\left(1+g_{t}\right)\left(1+\pi_{t}\right)} \\
g^{N F A} & \equiv
\end{aligned}
$$

In these equations, $n r_{t}^{N F A}$ denotes the nominal NFA return as share of GDP, $\pi$ is US inflation (or GDP deflator growth) and $g$ is real domestic GDP growth; i.e., $G D P_{t}=$ $G D P_{t-1}\left(1+g_{t}\right)\left(1+\pi_{t}\right)$. The dynamics of $n f a_{t}$ can therefore be written in terms of the trade balance $t b$, the real NFA return $r^{N F A}$ and a real GDP growth component $g^{N F A}$.

The real NFA return can also be broken down into a yield, valuation and inflation component as:

\footnotetext{
${ }^{10}$ The exact decomposition is given by

$$
\Delta \mathrm{nfa}_{t}=t b_{t}+k a_{t}+e o_{t}+\left\{n r_{t}^{N F A}-\frac{\pi_{t} \mathrm{nfa}_{t-1}}{\left(1+g_{t}\right)\left(1+\pi_{t}\right)}\right\}-\frac{g_{t} \mathrm{nfa}_{t-1}}{\left(1+g_{t}\right)\left(1+\pi_{t}\right)}-\frac{g_{t} \pi_{t} \mathrm{nfa}_{t-1}}{\left(1+g_{t}\right)\left(1+\pi_{t}\right)}
$$
}




$$
r_{t}^{N F A}=\underbrace{i b_{t}}_{\text {Yield }}+\underbrace{v_{t}}_{\text {Valuation }}-\underbrace{\mathrm{nfa}_{t-1}\left[\frac{\pi_{t}}{\left(1+g_{t}\right)\left(1+\pi_{t}\right)}\right]}_{\pi^{N F A}} .
$$

Furthermore, NFA valuation changes $\left(V_{t}\right)$ can be decomposed into a component due to changes in nominal exchange rates (which is a function of net positions in different currencies) and a residual attributed to asset price changes. The exchange rate component for assets, denoted $X R^{A}$ can be estimated as:

$$
X R_{t}^{A}=\sum_{i=1}^{N}\left(\frac{E_{t-1}^{i}}{E_{t}^{i}}-1\right) w_{t-1}^{A, i} A_{t-1}
$$

where the superscript $i$ indexes the currency of denomination of different assets, $w^{A, i}$ are currency shares of foreign assets, and $E^{i}$ is the end-of-period bilateral nominal exchange rate change of each currency $i$ vis-a-vis the US dollar. ${ }^{11}$ A similar expression applies for exchange rate valuation changes on the liability side $\left(X R_{t}^{L}\right)$ and the total exchange rate valuation change is given by $X R_{t}=X R_{t}^{A}-X R_{t}^{L}$.

The asset price component is then defined as $A P_{t}=V_{t}-X R_{t}$.

Financial returns can also be expressed as a percentage of the initial stock, with the corresponding real return on foreign assets defined as

$$
r_{t}^{A} \equiv \frac{I B_{t}^{A}+V_{t}^{A}}{A_{t-1}}-\pi_{t}
$$

where $I B^{A}$ is (interest and dividend) income from assets. An analogous formula defines returns on foreign liabilities $r_{t}^{L}$, and the return differential between foreign assets and liabilities is given by

$$
r_{t}=r_{t}^{A}-r_{t}^{L} .
$$

Finally, the return differential above can be decomposed into the yield (or income) differential, the exchange rate and the asset price (or valuation) differential:

$$
r_{t}=\underbrace{\left[\frac{I B_{t}^{A}}{A_{t-1}}-\frac{I B_{t}^{L}}{L_{t-1}}\right]}_{\text {Yield diff }}+\underbrace{\left[\frac{X R_{t}^{A}}{A_{t-1}}-\frac{X R_{t}^{L}}{L_{t-1}}\right]+\left[\frac{A P_{t}^{A}}{A_{t-1}}-\frac{A P_{t}^{L}}{L_{t-1}}\right]}_{\text {Valuation diff }} .
$$

\footnotetext{
${ }^{11}$ The focus is on currency positions in USD, EUR, GBP, CHF, JPY and a category of other foreign currencies, based on data availability. For the latter category, the nominal effective exchange rate of the US (against the rest of the world) is used.
} 


\section{Data}

We analyze a sample of 52 large economies, which account for more than 85 percent of world GDP, for the period 1990-2015. ${ }^{12}$ Balance of payments and IIP data are from the IMF's World Economic Outlook and International Financial Statistics databases, as well as the Wealth of Nations Database, compiled by Lane and Milesi-Ferretti (2017). Data on currency shares of foreign assets and liabilities come from Bénétrix et al. (2015).

\section{Stylized Facts}

We begin by documenting the behavior of the different components of NFA returns $\left(r_{t}^{N F A}\right)$ and of return differentials $\left(r_{t}\right)$ over time and across country groups.

\subsection{Trade balances and NFA returns}

\subsubsection{Averages}

Table 1 provides evidence of the relative magnitude of the different drivers of NFA positions over the sample period, including a breakdown around the Global Financial Crisis (GFC) to account for the marked drop in global interest rates afterwards. As shown, over the last quarter century, NFA returns have played an important role in driving NFA dynamics, with orders of magnitudes comparable or superior to those of the trade balance, on average. Moreover, NFA returns have become of greater importance in recent years, reflecting both greater valuation changes and income flows, in relation to GDP. However, return differentials have displayed remarkable stability when comparing pre- and post-crisis periods, including with regard to yield differentials. The latter suggests that the post-crisis drop in yields have been largely symmetric across the largest countries, thus maintaining yield differentials largely unchanged. Similarly, at an aggregate level, there is no evidence of greater (or smaller) role of exchange rate or assets price effects, despite the large movements, especially of the latter, after the GFC. ${ }^{13}$ The greater importance of NFA returns (which are defined in percent of GDP) along with stable return differentials indicates the growing role of stock positions in driving NFA returns.

A cross-section view of changes during the full sample period further illustrates the role of trade imbalances as a key driver of changes in NFA/GDP ratios (Figure 3, left panel). This has been partially offset by real NFA returns, as indicated by their negative correlation

\footnotetext{
${ }^{12}$ The sample includes all economies covered by the IMF's External Balance Assessment (International Monetary Fund (2017a)), plus Saudi Arabia, Hong Kong SAR and Singapore.

${ }^{13}$ This is partly due to the highly synchronized movement of asset prices in the post-GFC period.
} 
Table 1: Drivers of NFA/GDP, 1990-2015 (annual average of absolute value, in percent of GDP)

\begin{tabular}{llll}
\hline Period & $1990-2015$ & $1990-2007$ & $2008-15$ \\
\hline \hline Trade balance & 3.1 & 2.8 & $3.6^{*}$ \\
Real NFA return & 4.6 & 4.1 & $5.7^{* * *}$ \\
- Valuation change & 4.4 & 3.8 & $5.6^{* * *}$ \\
- Investment income & 1.4 & 1.2 & $1.7^{* *}$ \\
- Inflation & 0.4 & 0.4 & $0.5^{*}$ \\
\hline Return differential & 5.7 & 5.7 & 5.7 \\
- Yield diff. & 1.5 & 1.4 & 1.7 \\
- Exchange rate diff. & 2.0 & 1.9 & 2.3 \\
- Asset price diff. & 5.7 & 5.6 & 5.7 \\
\hline
\end{tabular}

Notes: GDP-weighted averages of the absolute value. The last row is calculated as a residual. Asterisks $* * *, * *$ and $*$ indicate whether the differences between period subsamples (1990-2007 vs 2008-15) are statistically significant at the 1,5 and 10 percent confidence levels respectively, with standard errors clustered at the country level.

Figure 3: NFA Components Across Countries, 1990-2015 (annual average, in percent of GDP)
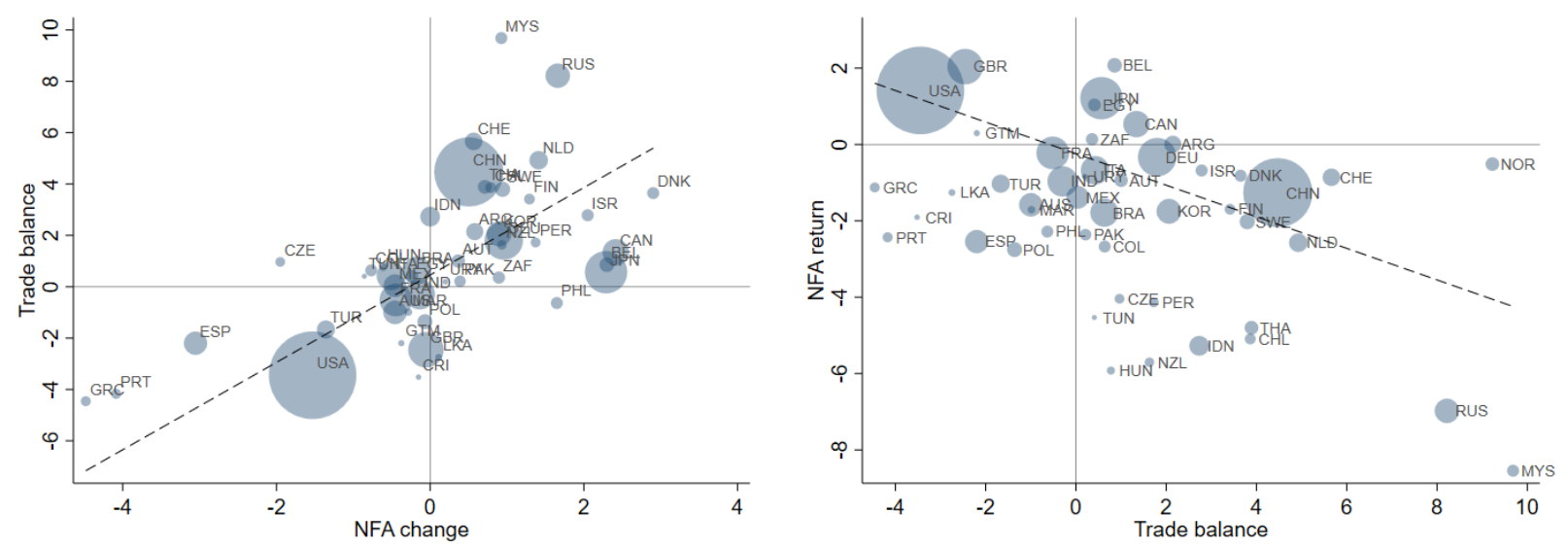

Notes: Bubble size is proportional to 2015 GDP in USD. Financial centers with very large gross IIP positions (Singapore, Hong Kong SAR and Ireland) are excluded. 
with trade balances (Figure 3, right panel). Causality, however, can run both ways: trade balances may respond to income arising from financial returns, and financial returns may reflect adjustment (including through depreciation and default) to trade imbalances. The econometric exercise in Section 5 sheds some light on the direction of causality.

\subsubsection{EMEs vs AEs}

Are return differentials different for, and do they play a different role in, EMEs? EMEs tend to be perceived as a riskier asset class, thus facing higher yields on their liabilities (for example, through higher sovereign spreads). But whether, and the extent to which, this should lead to different overall returns than those observed in AEs, especially over long time periods, is unclear. To the extent that higher yields on liabilities reflect default or inflation compensation, over time, the latter should materialize as valuation losses, thus leading to normal overall returns. Risk premia, on the other hand, could manifest itself as a sustained return differential.

The evidence points to sizable differences between return differentials for AEs and EMEs, as shown in Table 2, pointing to risk premia. Indeed, during the period 1990-2015, EM return differentials have been about 5 percentage points lower than those of AEs, indicating a large and statistically significant excess return. This larger differential reflects primarily differences in yields, followed by asset price changes, and only partially offset by exchange rate differentials. ${ }^{14}$ While yield differentials increased in the post-GFC period, on the back of lax monetary policy in AEs, these changes were offset by smaller exchange rate and asset price differentials.

Real NFA returns display a pattern similar to return differentials, with average NFA returns in EMEs about 2.3 percent of GDP lower than in AEs during the whole sample period. This difference has narrowed markedly in recent years, however, partly on account of the strengthening NFA positions in EMEs.

\subsubsection{Reserve-currency issuers}

Another key aspect often discussed in the literature relates to the differential returns faced by reserve-currency issuing countries. This has been extensively studied for the US-whose excess return differential has been dubbed an "exorbitant privilege"-but less so for other countries. We analyze potential differences between reserve-currency and non-reserve-currency countries, considering within the first group the US, UK, Euro Area (or Germany before

\footnotetext{
${ }^{14}$ Results on the decomposition of valuation changes into exchange rate and asset price changes rely on estimated currency exposures from Bénétrix et al. (2015).
} 
Table 2: NFA Returns and Return Differentials, Advanced and Emerging Markets (annual average, in percent of GDP and percent)

\begin{tabular}{lllllll}
\hline Sample & AEs & \multicolumn{5}{c}{ EMEs } \\
\hline Period & $1990-2015$ & $1990-2007$ & $2008-15$ & $1990-2015$ & $1990-2007$ & $2008-15$ \\
\hline \hline Trade balance & -0.7 & -0.6 & -1.0 & $2.2^{* *}$ & $2.1^{*}$ & $2.4^{* *}$ \\
Real NFA return & 0.4 & 0.4 & 0.5 & $-1.9^{* * *}$ & $-2.4^{* *}$ & $-1.4^{* *}$ \\
- Valuation change & 0.0 & 0.2 & -0.4 & -0.4 & -0.9 & 0.1 \\
- Investment income & 0.3 & 0.1 & 0.8 & $-1.7^{* * *}$ & $-1.8^{* * *}$ & $-1.6^{* * *}$ \\
- Inflation & -0.1 & -0.1 & -0.1 & -0.2 & -0.3 & -0.1 \\
\hline Return differential & 0.9 & 1.1 & 0.4 & $-4.2^{* * *}$ & $-3.8^{* *}$ & $-4.7^{* * *}$ \\
- Yield diff. & 0.6 & 0.5 & 0.9 & $-2.7^{* * *}$ & $-2.5^{* * *}$ & $-3.0^{* * *}$ \\
- Exchange rate diff. & -0.3 & -0.2 & -0.5 & 1.0 & $1.8^{* *}$ & 0.0 \\
- Asset price diff. & 0.6 & 0.8 & 0.1 & $-2.5^{* *}$ & $-3.1^{* *}$ & $-1.7^{* *}$ \\
\hline
\end{tabular}

Notes: GDP-weighted averages of the net value. Asterisks indicate whether the differences across country subsamples are statistically significant at the 1,5 and 10 percent confidence levels respectively, with standard errors clustered at the country level.

2001), Japan, and Switzerland. Table 3 differentiates between reserve-currency issuer countries and the rest, while Table 4 reports the same statistics for the reserve-currency issuing countries, individually.

Over the last quarter century, reserve-currency countries have displayed significantly higher real NFA returns - on average, 2.4 percentage points of GDP above those of other economies - reflecting a higher overall return differential of 3.6 percentage points. Differences in the average trade balance between the two groups (of about 3.7 percentage points of GDP) more than offset NFA return differentials.

Interestingly, the difference in NFA returns between these two groups of countries has fallen considerably in the post-crisis period (from about 3 to about 1 percent of GDP) while return differentials have been more stable (with the difference between the two groups moving marginally, from 3.6 to 3.4 percent). This reflects that stock positions of reserve-currency countries have, on average, weakened in recent years, while stock positions of non-reserve countries have strengthened.

Among reserve-currency economies, the US stands out, followed by the UK, by displaying a significantly higher return differential (averaging 3.3 percent over the last 25 years) than those of other reserve-currency countries (Table 4). ${ }^{15}$ Moreover, the US' return differential is

\footnotetext{
${ }^{15}$ The US estimate is broadly consistent with those found by Obstfeld and Rogoff (2005) and Lane and Milesi-Ferretti (2009), while somewhat larger than those of Gourinchas and Rey (2007) and Curcuru et al. (2008). Sample periods vary somewhat across studies, however. Data from the Bureau of Economic Analysis (available for 2003-15), which disaggregates the stock-flow reconciliation residual, leads to similar results, with a slightly lower NFA return (about 0.9 percent) and return differential (3.1 percent).
} 
Table 3: NFA Returns and Return Differentials, Reserve-Currency Countries (annual average, in percent of GDP and percent)

\begin{tabular}{lllllll}
\hline Countries & \multicolumn{3}{l}{ Reserve issuers } & \multicolumn{3}{l}{ Non-reserve issuers } \\
\hline Period & $1990-2015$ & $1990-2007$ & $2008-15$ & $1990-2015$ & $1990-2007$ & $2008-15$ \\
\hline \hline Trade balance & -1.5 & -1.4 & -1.7 & $2.2^{* * *}$ & $2.0^{* * *}$ & $2.5^{* * *}$ \\
Real NFA return & 0.8 & 1.0 & 0.4 & $-1.6^{* * *}$ & $-2.0^{* * *}$ & -0.8 \\
- Valuation change & 0.1 & 0.4 & -0.8 & -0.3 & -0.8 & 0.6 \\
- Investment income & 0.7 & 0.6 & 1.1 & $-1.5^{* * *}$ & $-1.5^{* * *}$ & $-1.4^{* * *}$ \\
- Inflation & -0.0 & -0.0 & -0.1 & -0.3 & -0.2 & -0.0 \\
\hline Return differential & 1.1 & 1.5 & 0.2 & $-2.5^{* *}$ & $-2.1^{* *}$ & $-3.2^{* *}$ \\
- Yield diff. & 0.9 & 0.9 & 1.1 & $-1.9^{* * *}$ & $-1.6^{* * *}$ & $-2.3^{* * *}$ \\
- Exchange rate diff. & -0.3 & -0.1 & -0.6 & 0.5 & $0.7^{*}$ & 0.0 \\
- Asset price diff. & 0.6 & 0.9 & -0.2 & -1.1 & -1.3 & -0.9 \\
\hline
\end{tabular}

Notes: GDP-weighted averages. Trade balance and NFA returns (and its components) are reported as percent of GDP. Return differentials (and their components) are reported as percentages. Asterisks $* * *,{ }^{* *}$ and $*$ indicate whether the differences across country subsamples are statistically significant at the 1,5 and 10 percent confidence levels respectively. Standard errors are calculated with the Cochrane-Orcutt procedure to correct for autocorrelation.

Table 4: NFA Returns and Return Differentials, Reserve-Currency Countries, 1990-2015

\begin{tabular}{llllllll}
\hline Country & $n f a$ & $t b$ & $r^{N F A}$ & $r$ & Yield & $X R$ & $A P$ \\
\hline \hline United States & -17.8 & -3.5 & 1.6 & $3.3^{* *}$ & $1.4^{* * *}$ & -0.3 & $2.2^{*}$ \\
Euro Area & -13.2 & 0.8 & -0.9 & -0.3 & 0.2 & -0.2 & -0.4 \\
United Kingdom & -8.0 & -2.5 & 2.1 & 0.6 & $0.3^{*}$ & 0.1 & 0.3 \\
Japan & 36.6 & 0.6 & 0.9 & -1.6 & $1.7^{* * *}$ & -0.3 & $-3.4^{* *}$ \\
Switzerland & 103.4 & 5.7 & -1.8 & $-1.3^{* *}$ & $0.8^{* *}$ & -1.0 & -1.1 \\
\hline
\end{tabular}

Notes: Annual averages. The sample period for the Euro Area is 2001-15.

NFA, TB and NFA return are reported as percent of GDP. Other variables are in percent. Asterisks ${ }^{* * *},{ }^{* *}$ and ${ }^{*}$ indicate whether return differentials are significantly different from zero at the 1, 5 and 10 percent confidence levels respectively. Standard errors are calculated with the Cochrane-Orcutt procedure to correct for autocorrelation. 
sufficiently high to more than offset its negative NFA position, leading to an overall positive NFA return (equivalent to about a third of the average trade deficit). This return differential mostly reflects a sizable yield differential (due to lower yields on liabilities than on assets) but also a large asset price differential, partly resulting from a long net equity position and a short net debt position. As discussed above, however, results on the decomposition of valuation changes into exchange rate and asset price changes should be interpreted with caution as they rely on estimates of currency exposures from Bénétrix et al. (2015) being precise.

The UK is another interesting case, with a significantly smaller return differential in comparison to the US (of about 0.6 percent, on average) but still a sizable NFA return (of about 2 percent of GDP, on average), on account of the country's large gross positions (in excess of ten times its GDP).

Japan stands out with a negative return differential (-1.6 percent, on average) on account of large negative asset price valuation changes, which more than offset the systematic positive yield differential. Interestingly, however, Japan displays an economically sizable NFA return (of 1.2 percent, on average) reflecting a positive NFA position and, more importantly, large gross positions in debt assets with a large yield differential, relative to equity positions (where asset price movements dominate).

Switzerland shows a pattern similar to Japan's, with a negative return differential (-1.6 percent on average) on account of both negative exchange rate and asset price differentials than more than offset the positive yield differential, but an overall small positive NFA return. ${ }^{16}$

Meanwhile, the euro area (as a whole) shows little sign of a non-zero return differential, possibly reflecting stark differences among countries within the currency area. ${ }^{17}$

\subsection{External positions}

As a first exploration of the driving forces and stabilizing mechanisms of NFA, Table 5 presents similar summary statistics of drivers of the NFA/GDP ratio conditional on the sign of the trade balance and the average NFA position during the sample period. The comparison of averages across countries with different trade balances provides a first glance at the stabilizing role of NFA returns, although causality cannot be inferred from this.

\footnotetext{
${ }^{16}$ The offsetting nature of the yield differential and the remaining return differential is partly due to Switzerland's relatively low inflation and large portfolio equity retained earnings liabilities (which, unlike FDI retained earnings, are not recorded in the income balance). Both factors generate both an inflated income balance and compensating valuation losses.

${ }^{17}$ Results for the euro area should also be interpreted more cautiously given the shorter time span of the data.
} 
Table 5: NFA Returns and Return Differentials, External Position, 1990-2015

\begin{tabular}{lllll}
\hline Sample & TB surplus & TB deficit & Creditors & Debtors \\
\hline \hline Trade balance & 2.3 & $-2.8^{* * *}$ & 2.8 & $-1.4^{* * *}$ \\
Real NFA return & -1.0 & $0.9^{* *}$ & -0.5 & 0.1 \\
- Valuation change & -0.5 & $0.5^{* *}$ & -0.8 & $0.3^{* *}$ \\
- Income balance & -0.3 & 0.1 & 0.9 & $-0.6^{* *}$ \\
- Inflation & 0.1 & $-0.4^{* * *}$ & 0.5 & $-0.4^{* * *}$ \\
\hline Return differential & -2.1 & $1.9^{* * *}$ & -2.5 & $0.8^{* *}$ \\
- Yield diff. & -1.0 & $0.8^{* *}$ & -0.6 & 0.0 \\
- Exchange rate diff. & 0.1 & -0.1 & -0.4 & 0.2 \\
- Asset price diff. & -1.4 & $1.2^{* *}$ & -1.7 & $0.6^{*}$ \\
\hline
\end{tabular}

Notes: GDP-weighted averages. Trade balance and NFA returns (and its components) are reported as percent of GDP. Return differentials (and their components) are reported as percentages. Asterisks indicate whether the differences across country subsamples are statistically significant at the 1,5 and 10 percent confidence levels respectively, with standard errors clustered at the country level.

Countries with trade surpluses (on average) tended to experience lower return differentials, and vice versa.

Meanwhile, a breakdown into creditor and debtor economies (based on their average NFA position during the sample period) highlights the key role of trade imbalances in driving NFA positions (consistent with Figure 3) while pointing to the stabilizing role of return differentials, with creditors running negative differentials and debtors positive ones. ${ }^{18}$ This is also visible, although less striking, in the difference of NFA returns between the two groups. These statistics, however, should be interpreted with caution as NFA positions of some countries have changed markedly during the period of analysis, in which case average NFA positions may carry limited information for drawing conclusions about the relationship with return differentials. A more granular and formal approach that exploits the information embedded in the time series is conducted next.

\section{$5 \quad$ NFA-Stabilizing Mechanisms}

This section formalizes the above evidence on the stabilizing role of NFA returns by means of a simple econometric approach. Specifically, we consider a panel-regression specification

\footnotetext{
${ }^{18}$ This seems to be primarily explained by asset price differentials, with additional (but not primary) contributions from both yield and exchange rate differentials.
} 
of the form:

$$
y_{c, t}=\beta \mathrm{nfa}_{c, t-1}+\delta^{\prime} X_{c, t}+\kappa_{c}+u_{c, t}
$$

where $c$ indexes countries, $y_{c, t}$ is either the change in $n f a_{c, t}$ (to study the dynamic properties of nfa) or one of its drivers from equation (2) and (3), $X_{c, t}$ is a vector of relevant controls (mostly interaction terms with country groups), $\kappa_{c}$ is a country fixed effect, and $u_{c t}$ is an independent mean-zero error term, which can have non-zero correlation within countries. Our interest lies on the coefficient $\beta$.

First we focus on the dynamic properties of nfa. A negative (and less than one in absolute value) $\beta$ coefficient would indicate a stable dynamics-that is, an underlying process leading to a finite steady steady state $n f a$ level-despite persistent drivers captured in the fixed effects. ${ }^{19}$

Next, we study the stabilizing channels, by exploring the drivers of $\Delta$ nfa (i.e., $t b, r^{N F A}$ and $g^{N F A}$ ). We test the null hypothesis that a given driver, $y_{t}$, does not adjust to changes in the external stock position $(\beta=0)$ against the alternative that $\beta \neq 0$. Negative values for $\beta$ would indicate that a given channel provides stabilization of the NFA position within a country. Consistent with the analysis in Section 4, observations are weighted by current GDP of each country, although alternative (unweighted) estimations are explored in Appendix A to shed light on the role of large versus small economies. ${ }^{20}$

\subsection{Average effects}

Table 6 shows estimated coefficients for regression (5), using the different components of NFA dynamics (equations (2) and (3)) as the dependent variable, for the full sample. As indicated by the negative coefficient on the lagged $n f a$, after controlling for country fixed effects, NFA positions display stable dynamics on average, although with a high degree of

\footnotetext{
${ }^{19}$ Specifically, a steady state exists if $-1<\beta<0$, and it is given by $\operatorname{nf} a_{s s}=-\kappa_{c} / \beta$ (for the baseline case $\delta=0)$. The underlying assumption is that, while persistent drivers of the NFA can be different in magnitude across countries, the speed of convergence to steady steady is similar across them. This is relaxed later, as different country groups are studied.

${ }^{20}$ As a robustness check, Appendix (A.2) presents an alternative approach that imposes a linear constraint on the coefficients consistent with the BOP identity $\triangle \mathrm{nfa}=t b+r^{N F A}+g^{N F A}$. Specifically, the following system of four (seemingly unrelated) equations is estimated:

$$
\left\{\begin{array}{ccc}
\triangle \mathrm{nfa} & = & \beta \text { L.nfa } \\
t b & = & \beta_{T B} \text { L.nfa } \\
r^{N F A} & = & \beta_{N F A r e t} \text { L.nfa } \\
g^{N F A} & = & \beta_{g} \text { L.nfa }
\end{array}\right\},
$$

subject to $\beta=\beta_{T B}+\beta_{N F \text { Aret }}+\beta_{g}$.
} 
Table 6: NFA Dynamics and Stabilizing Components

\begin{tabular}{cccccccc}
\hline & $\Delta$ nfa & $t b$ & $r^{N F A}$ & $g^{N F A}$ & $v a l$ & $i b$ & $\pi^{N F A}$ \\
\hline \hline L.nfa & $-0.070^{* * *}$ & 0.020 & $-0.064^{* * *}$ & -0.015 & $-0.065^{* * *}$ & $0.018^{* *}$ & $-0.016^{* * *}$ \\
& $(0.019)$ & $(0.014)$ & $(0.017)$ & $(0.014)$ & $(0.014)$ & $(0.009)$ & $(0.001)$ \\
$R^{2}$ & 0.074 & 0.647 & 0.126 & 0.100 & 0.073 & 0.820 & 0.897 \\
$N$ & 1288 & 1288 & 1288 & 1288 & 1288 & 1288 & 1288 \\
\hline
\end{tabular}

Notes: All variables are expressed in percent of GDP. Coefficients are estimated by a panel regression with country fixed effects. In all the regression results tables that follow, asterisks indicate statistical significance at the 1, 5 and 10 percent confidence levels respectively.

Standard errors are clustered at the country level. The real growth and inflation components enter with a negative sign.

persistence. Specifically, a 10 percent higher NFA leads on expectation to a -0.7 percent change in the NFA position in the following year.

Taking these estimates of the average underlying NFA process at face value, the implied steady-state NFA position for each country can be inferred. As shown in Figure 4, for most countries, such steady state level is close to the observed value for 2015, indicating that persistent drivers of NFA positions (captured in the fixed effect) are largely offset by meanreverting forces (see further discussion below on these stabilizing mechanisms). Countries displaying this feature include the US, UK (despite their persistent current account deficits), China and Japan. Noticeable exceptions include Hong Kong SAR, Norway, Germany and the Netherlands. Meanwhile, Singapore, Switzerland and Belgium are cases where NFA positions would narrow relative to the 2015 level. ${ }^{21}$

The results also indicate that NFA returns, as opposed to trade balances, are the main NFA-stabilizing mechanism. That is, there is no evidence that the trade balance responds to changes in net external wealth (second column in Table 6), but there is evidence that NFA returns are negatively related to the existing level of external wealth (third column). In particular, a 10 percent higher NFA predicts a -0.6 percent of GDP lower NFA return. Meanwhile, we find evidence of high persistence in trade imbalances but not in other components (Table7). These two pieces of evidence highlight the key finding of the paper: while persistent trade imbalances have led to diverging $n f a$ positions, NFA returns have played an important, although insufficient, stabilizing role. ${ }^{22}$

Appendix A.2 shows that these results are robust to a number of variations, such as:

- excluding the US, or running an unweighted regression, to limit the importance of large

\footnotetext{
${ }^{21}$ Ireland is an outlier, reflecting significant, well-known, mismeasurement issues related to the presence of large multinational corporations. See, for example, International Monetary Fund (2017b) and Lane et al. (2017).

${ }^{22}$ We find no evidence of a change in the regression coefficients after the GFC (result not reported).
} 
Figure 4: Implied steady-state NFA positions

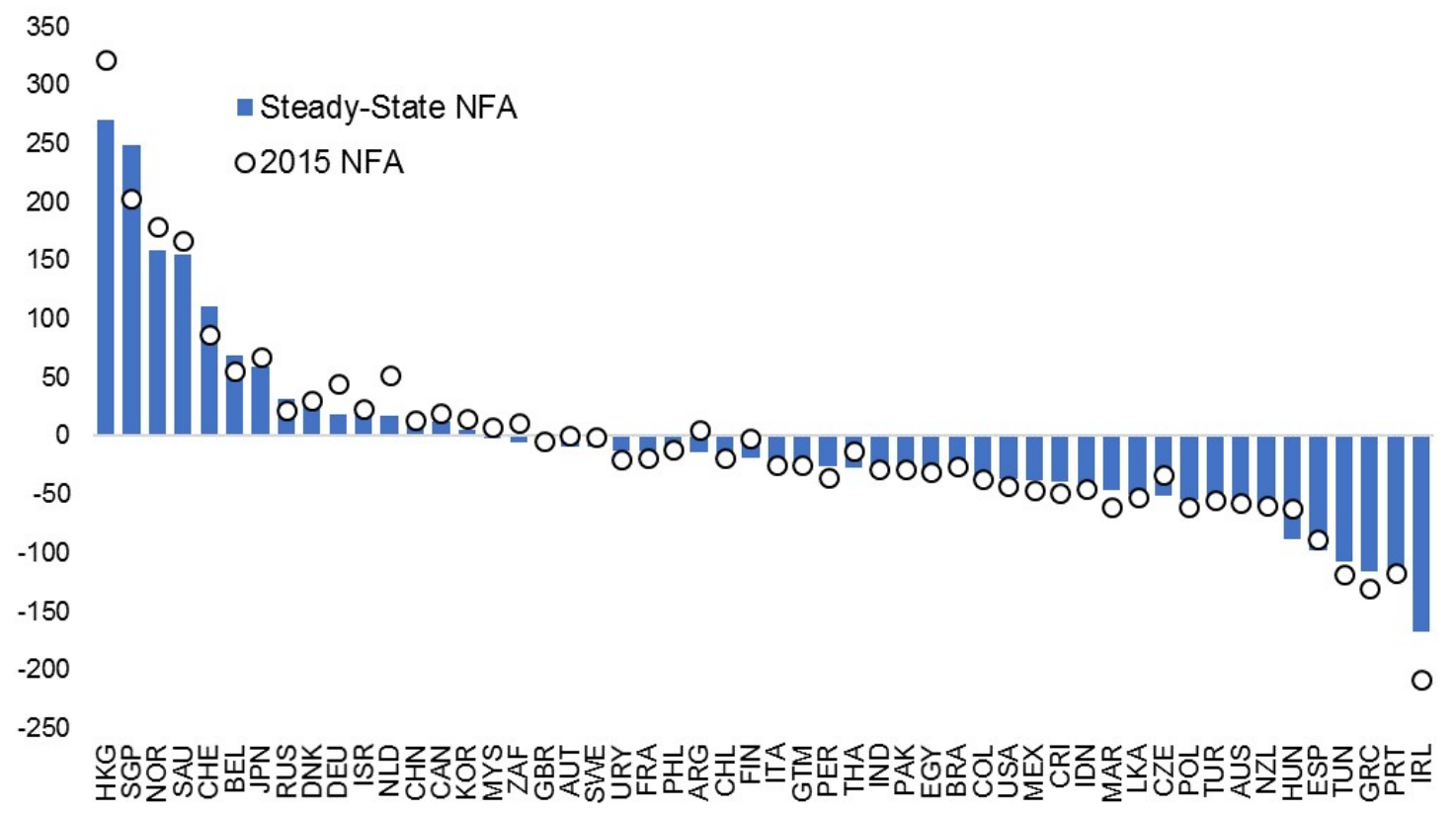

Notes: Percentage of GDP. The steady-state NFA is equal to minus the country fixed effect divided by $\beta^{N F A}$, from column 1 in Table 6 . These implied stead-state values do not reflect, and may be different from, IMF country team projections.

economies in the results;

- focusing on 5-year averages to reduce year-to-year noise in the data (e.g., from errors and omissions);

- treating BOP errors and omissions as part of valuation changes, as mismeasurement can be due to the current account or to the financial account;

- computing valuation changes on the basis of variables denominated in local currency (instead of US dollars);

- estimating the regressions with a system of seemingly unrelated regressions (imposing equation 2 as a constraint) and assuming panel-corrected errors;

- excluding economies with large gross stock positions (often referred to as 'financial centers'). This is particularly important as the large stocks and flows in these economies may reflect tax arbitrage, which can distort measured NFA returns (although not necessarily the estimated coefficient on the lagged NFA position). ${ }^{23}$

\footnotetext{
${ }^{23}$ As discussed in Lane et al. (2017), profit shifting towards low tax rate jurisdictions tends to boost the trade balance of the latter economies, with an offsetting effect on the income balance (i.e., the current
} 
Table 7: NFA Dynamics and Stabilizing Components, Autocorrelation

\begin{tabular}{lcccccc}
\hline & $t b$ & $r^{N F A}$ & $g^{N F A}$ & $v a l$ & $i b$ & $\pi^{N F A}$ \\
\hline \hline L.nfa & $-0.007^{* *}$ & $-0.064^{* * *}$ & -0.016 & $-0.065^{* * *}$ & 0.004 & $-0.009^{* * *}$ \\
& $(0.003)$ & $(0.019)$ & $(0.013)$ & $(0.016)$ & $(0.002)$ & $(0.001)$ \\
lag dep. var. & $0.830^{* * *}$ & -0.015 & 0.148 & -0.016 & $0.783^{* * *}$ & $0.455^{* * *}$ \\
& $(0.021)$ & $(0.042)$ & $(0.090)$ & $(0.041)$ & $(0.059)$ & $(0.034)$ \\
$R^{2}$ & 0.881 & 0.129 & 0.117 & 0.075 & 0.925 & 0.926 \\
$N$ & 1286 & 1236 & 1237 & 1236 & 1287 & 1237 \\
\hline
\end{tabular}

Notes: All variables are expressed in percent of GDP. Standard errors are clustered at the country level. The real growth and inflation components enter with a negative sign.

Table 8: Stabilizing Return Differentials

\begin{tabular}{llllllll}
\hline & $r^{A}$ & $r^{L}$ & $r$ & Yield diff. & XR diff & AP diff & AP liab. \\
\hline \hline L.nfa & -0.026 & $0.075^{* *}$ & $-0.100^{* * *}$ & -0.006 & 0.006 & $-0.099^{* * *}$ & $0.066^{* *}$ \\
& $(0.027)$ & $(0.034)$ & $(0.025)$ & $(0.004)$ & $(0.007)$ & $(0.023)$ & $(0.027)$ \\
$R^{2}$ & 0.081 & 0.045 & 0.193 & 0.78 & 0.092 & 0.156 & 0.05 \\
$N$ & 1247 & 1247 & 1247 & 1247 & 1247 & 1247 & 1247 \\
\hline
\end{tabular}

Notes: $r^{A}:$ return on assets, $r^{L}:$ return on liabilities, $r$ : return differential, XR: exchange rate, AP: asset prices. Standard errors are clustered at the country level.

We also find that the stabilizing effect of NFA returns operates through NFA valuation changes, as opposed to the income balance, and in particular asset prices. A striking implication of this result, also found for the US by Gourinchas and Rey (2014), is that net valuation changes are predictable for a given NFA position. ${ }^{24}$

Table 8 provides a further breakdown of returns into their components. As shown, NFA stabilization comes mainly from the return on liabilities-which increases with NFA positions. ${ }^{25}$ This leads to a sizable overall negative correlation between return differentials and NFA positions. Specifically, in this baseline specification, a 10 percent of GDP higher NFA is associated with a 1 percent lower return differential. While this qualitative result is robust across specifications, the above estimate seems to be an upper bound, as alternative specifications point to a somewhat weaker relationship (see Appendix A). In particular, the coefficient is reduced by half in an unweighted regression, suggesting the result is partly

account balance remains broadly unchanged). In such cases, the measured NFA returns could be distorted, and the breakdown between trade and NFA return channels could be less informative.

${ }^{24}$ As noted by Gourinchas and Rey (2014), this posed a significant challenge to the profession in terms of modeling a process of external adjustment with expected valuation changes.

${ }^{25}$ This result is consistent with the notion that most individual economies are too small to affect global returns (i.e., their own returns on foreign assets). Different results may arise if credit countries are assessed collectively. 
driven by large economies.

Decomposing return differentials into yields, exchange rate and asset price differentials sheds further light on the mechanism behind the above result. As shown in Table 8 stabilization appears to come from liability prices. That is, liabilities of countries which accumulate foreign wealth tend to gain value (mainly through equity prices), generating a negative return differential for those countries. Reassuringly, this result also holds in the reduced sample of countries which provided hard data on the decomposition of valuation changes into exchange rates, asset prices, and the reconciliation residual. Hence, it is unlikely to be an artifact of the asset price component being estimated as a residual in our methodology.

\subsection{EMEs vs AEs}

Similarly to the stylized facts presented in Section 4, this section explores differences in NFA dynamics between AEs and EMEs with the above describe econometric approach. The results (Table 9) indicate that the speed of NFA adjustment is significantly higher for (individual) EMEs than for AEs by approximately a factor of 5 (i.e., a half-life for shocks to the NFA of about 13 years for AEs in contrast to about 2.5 years for EMEs). For both groups, external adjustment comes from NFA returns. Moreover, this result holds not only for debtor EMEs, for which credit constraints may have an important bearing on the speed of adjustment, but also for creditor EMEs, as indicated by the insignificant interaction coefficient.

\subsection{Reserve currencies}

Finally, Table 10 tests whether reserve-currency (RC) economies, as previously defined, display different NFA dynamics. On average, RC issuers appear to adjust at a slower pace than other economies (implying a half-life of about 16 years, against 6 years for other economies), although the difference between the two groups is only marginally statistically significant. 
Table 9: NFA Dynamics and Stabilizing Components, AE/EME

\begin{tabular}{lllllll}
\hline & AE/EME & \multicolumn{3}{c}{ AE/EME \& creditor/debtor } \\
\hline & $\Delta \mathrm{nfa}$ & $t b$ & $r^{N F A}$ & $\Delta \mathrm{nfa}$ & $t b$ & $r^{N F A}$ \\
\hline \hline L.nfa & $-0.051^{* *}$ & 0.020 & $-0.053^{* * *}$ & $-0.056^{* *}$ & 0.026 & $-0.068^{* *}$ \\
& $(0.019)$ & $(0.016)$ & $(0.018)$ & $(0.025)$ & $(0.021)$ & $(0.031)$ \\
L.nfa_EM & $-0.187^{* * *}$ & -0.001 & $-0.106^{* * *}$ & $-0.182^{* * *}$ & -0.033 & $-0.081^{*}$ \\
& $(0.042)$ & $(0.029)$ & $(0.037)$ & $(0.053)$ & $(0.035)$ & $(0.048)$ \\
L.nfa_creditor & & & & 0.01 & -0.012 & 0.028 \\
& & & & $(0.040)$ & $(0.031)$ & $(0.037)$ \\
L.nfa_cred_EM & & & & -0.008 & 0.106 & -0.061 \\
& & & & $(0.072)$ & $(0.065)$ & $(0.081)$ \\
$R^{2}$ & 0.088 & 0.647 & 0.131 & 0.088 & 0.650 & 0.132 \\
$N$ & 1288 & 1288 & 1288 & 1288 & 1288 & 1288 \\
\hline
\end{tabular}

Notes: Standard errors are clustered at the country level.

Table 10: Stabilizing Components, Reserve Currencies

\begin{tabular}{lllllll}
\hline \multicolumn{5}{c}{ Baseline } & \multicolumn{3}{l}{$\mathrm{RC}$} \\
\hline \hline L.nfa & $\Delta \mathrm{nfa}$ & $t b$ & $r^{N F A}$ & $\Delta \mathrm{nfa}$ & $t b$ & $r^{N F A}$ \\
& $-0.070^{* * *}$ & 0.02 & $-0.064^{* * * *}$ & $-0.110^{* * *}$ & $0.023^{* *}$ & $-0.088^{* * *}$ \\
L.nfa_RC & $(0.019)$ & $(0.014)$ & $(0.017)$ & $(0.030)$ & $(0.010)$ & $(0.018)$ \\
& & & & $0.068^{*}$ & -0.014 & 0.045 \\
$R^{2}$ & & & & $(0.035)$ & $(0.023)$ & $(0.030)$ \\
$N$ & 0.074 & 0.647 & 0.126 & 0.082 & 0.654 & 0.129 \\
\hline
\end{tabular}

Notes: Standard errors are clustered at the country level.

\section{$6 \quad$ NFA Returns as Insurance}

Another relevant angle of the potentially stabilizing role of NFA returns relate to their offsetting role of income shocks. This section analyzes such insurance role against both domestic and global income shocks. To do so, the following panel regression model is estimated:

$$
y_{c, t}=\alpha+\beta G D P g r_{c, t}+\delta^{\prime} X_{c, t}+\kappa_{c}+u_{c, t},
$$

where the dependent variable is either the 5-year average NFA return, in percent of domestic GDP, or one of its components (see equation (3)); GDPgr $r_{c, t}$ is the contemporaneous 5-year average domestic GDP growth, and other variables follow the description of the previous section. Throughout this section, the focus is on 5-year intervals, which increases the sig- 
Table 11: Insurance against Domestic GDP Shocks

\begin{tabular}{lllll}
\hline & $r^{N F A}$ & $i b$ & $v a l$ & $\pi^{N F A}$ \\
\hline \hline$g \_5$-year & $-0.633^{* * *}$ & -0.088 & $-0.505^{* * *}$ & $-0.177^{* *}$ \\
& $(0.136)$ & $(0.062)$ & $(0.153)$ & $(0.081)$ \\
$R^{2}$ & 0.508 & 0.87 & 0.315 & 0.839 \\
$N$ & 1078 & 1084 & 1078 & 1084 \\
\hline
\end{tabular}

Notes: The time period is 5 years. A negative coefficient indicates that countries receive insurance against GDP growth shocks. Standard errors are clustered at the country level. The inflation component enters with a negative sign.

Table 12: Insurance against Domestic GDP Shocks, Return Differentials

\begin{tabular}{lllll}
\hline & $r$ & Yield diff. & XR diff & AP diff \\
\hline \hline$g \_5$-year & $-0.726^{* * *}$ & -0.091 & -0.200 & $-0.460^{*}$ \\
& $(0.182)$ & $(0.060)$ & $(0.134)$ & $(0.233)$ \\
$R^{2}$ & 0.586 & 0.877 & 0.262 & 0.538 \\
$N$ & 1077 & 1042 & 1085 & 1042 \\
\hline
\end{tabular}

Notes: The time period is 5 years. A negative coefficient indicates that countries receive insurance against GDP growth shocks. Standard errors are clustered at the country level. The inflation component enters with a negative sign.

nificance of the relationships. That is, we consider the effect of 5-year average GDP growth shocks on NFA returns and their components.

\subsection{Insurance against domestic shocks}

Table 11 displays the results for the case of domestic GDP growth shocks. As indicated by the large and statistically significant coefficient, NFA returns play an important insurance

role against these shocks. Specifically, a 1 percent drop in the 5-year average GDP growth is associated with an average positive NFA return of 0.6 percent of GDP over the same period. This effect comes largely from valuation changes, supported by more marginal effects through inflation and income.

The result is also visible in return differentials, which display a similar association with real GDP growth (Table 12). Again, the component that provides more insurance is the asset price differential, although the exchange rate differential and, to a minor extent, the yield differential also contribute.

The above results point to average effects. However, as shown on Figure 5, which displays results of the slope coefficient for individual country regressions, this is a broad phe- 
Figure 5: Beta of NFA returns on GDP growth

(5-year intervals)

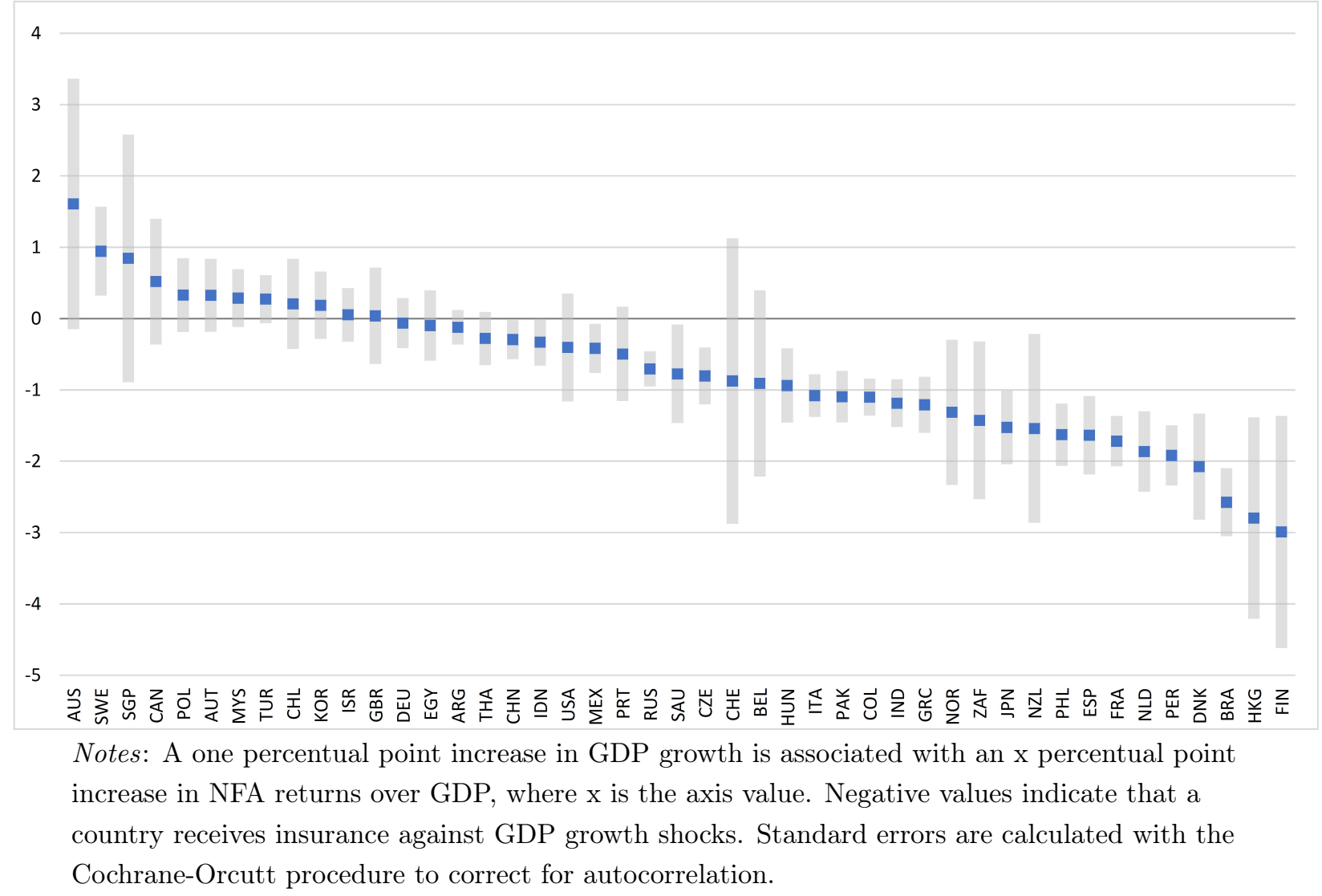

nomenon. Indeed, for the majority of countries, NFA returns provide insurance against domestic shocks-and for others, the effects are not statistically different for zero. This applies to AEs, but also to EMEs, mainly on account of the role of asset price valuation changes-as many EMEs faced adverse aggregate currency mismatches for much of the sample period. ${ }^{26}$

\subsection{Global insurance providers}

Finally, we consider the role of countries in providing insurance to the rest of the world, with a particular focus on reserve-currency countries. To this end, we modify equation (6) as:

$$
y_{c, t}=\alpha+\beta G D P g r_{c, t}^{R O W}+\delta^{\prime} X_{c, t}+\kappa_{c}+u_{c, t},
$$

where the dependent variable is the 5-year average NFA return, expressed in either percent of world or domestic GDP, and GDPgr $r_{c, t}^{R O W}$ is the 5-year average GDP growth in the rest

\footnotetext{
${ }^{26}$ See related discussion in International Monetary Fund (2016).
} 
Table 13: Providers of Insurance

\begin{tabular}{|c|c|c|c|c|c|c|}
\hline \multirow{2}{*}{$\overline{g^{R O W}}$} & \multicolumn{6}{|c|}{ NFA Return over World GDP, 5-year intervals } \\
\hline & $\begin{array}{l}-0.012^{* * *} \\
(0.001)\end{array}$ & $\begin{array}{l}-0.012^{* * *} \\
(0.001)\end{array}$ & $\begin{array}{l}-0.012^{* * *} \\
(0.001)\end{array}$ & $\begin{array}{l}-0.012^{* * *} \\
(0.001)\end{array}$ & $\begin{array}{l}-0.012^{* * *} \\
(0.001)\end{array}$ & $\begin{array}{l}-0.012^{* * * *} \\
(0.001)\end{array}$ \\
\hline$g^{R O W}{ }_{-} \mathrm{RC}$ & $\begin{array}{l}0.066^{* * *} \\
(0.018)\end{array}$ & $\begin{array}{l}0.053^{* * *} \\
(0.001)\end{array}$ & $\begin{array}{l}0.066^{* * *} \\
(0.019)\end{array}$ & $\begin{array}{l}0.231^{* *} \\
(0.090)\end{array}$ & $\begin{array}{l}0.066^{* * *} \\
(0.018)\end{array}$ & $\begin{array}{l}0.066^{* * *} \\
(0.018)\end{array}$ \\
\hline$g^{R O W}=\mathrm{US}$ & & $\begin{array}{l}0.281^{* * *} \\
(0.000)\end{array}$ & & & & \\
\hline$g^{R O W} \_\mathrm{EA}$ & & & $\begin{array}{l}-0.017 \\
(0.019)\end{array}$ & & & \\
\hline$g^{R O W} \_\mathrm{UK}$ & & & & $\begin{array}{l}-0.178^{*} \\
(0.090)\end{array}$ & & \\
\hline$g^{R O W} \_\mathrm{JAP}$ & & & & & $\begin{array}{l}-0.005 \\
(0.018)\end{array}$ & \\
\hline$g^{R O W} \_\mathrm{CHE}$ & & & & & & $\begin{array}{l}-0.052^{* * *} \\
(0.018)\end{array}$ \\
\hline$R^{2}$ & 0.517 & 0.569 & 0.517 & 0.549 & 0.517 & 0.517 \\
\hline$N$ & 870 & 870 & 870 & 870 & 870 & 870 \\
\hline
\end{tabular}

Notes: RC: reserve-currency issuer countries. A one percent point increase in rest-of-the-world GDP growth $\left(g^{R O W}\right)$ is associated with an x percentual point increase in NFA returns over world GDP, where $\mathrm{x}$ is the coefficient value. Positive coefficients indicate that countries provide insurance to the rest of the world. Standard errors are clustered at the country level.

of the world.

Table 13 reports results for the case of NFA returns expressed in percent of world GDP (that is, NFA returns as previously defined are rescaled to $\left.r_{c, t}^{N F A} \frac{G D P_{c, t}}{G D P_{W, t}}\right)$. Reserve-currency countries are found to be providers of insurance against income shocks to the rest of the world. This reflects that their own valuation effects are positively correlated with GDP growth in the rest of the world, implying a negative valuation for the latter group of countries (given that valuation effects aggregate to zero globally). As a group, reserve-currency economies are found to transfer, on average, 0.26 percent of world GDP in wealth to non-reserve countries when GDP growth in the latter group slows down by 1 percent. ${ }^{27}$

Further exploration of the individual roles of the different reserve-currency countries shows that the US stands out, contributing with 0.32 percent of world GDP, while Switzerland appears to play a more limited role, although these results partly reflect differences in the size of the insurer economies, as discussed below. ${ }^{28}$ Correspondingly, other (non-reserve

\footnotetext{
${ }^{27}$ This results from running regression (7) treating the set of reserve countries as a single country, and allowing it to have a different slope coefficient. Regression results are not reported.

${ }^{28}$ Specification (7) is modified to include interaction terms between $g_{c, t}^{R O W}$ and a dummy for the set of reserve countries, as well as individual reserve country dummies, as regressors. The total contribution of
} 
Table 14: Providers of Insurance, Relative to Domestic GDP

\begin{tabular}{|c|c|c|c|c|c|c|}
\hline & & NFA Retur & over Dom & stic GDP, 5 & -year interv & \\
\hline$g^{R O W}$ & $\begin{array}{l}-0.869^{* * *} \\
(0.129)\end{array}$ & $\begin{array}{l}-0.869^{* * *} \\
(0.130)\end{array}$ & $\begin{array}{l}-0.869^{* * *} \\
(0.130)\end{array}$ & $\begin{array}{l}-0.869^{* * *} \\
(0.130)\end{array}$ & $\begin{array}{l}-0.869^{* * *} \\
(0.130)\end{array}$ & $\begin{array}{l}-0.869^{* * *} \\
(0.130)\end{array}$ \\
\hline$g^{R O W} \_\mathrm{RC}$ & $\begin{array}{l}1.529 * * * \\
(0.133)\end{array}$ & $\begin{array}{l}1.505^{* * *} \\
(0.131)\end{array}$ & $\begin{array}{l}1.542^{* * *} \\
(0.134)\end{array}$ & $\begin{array}{l}1.669^{* * *} \\
(0.350)\end{array}$ & $\begin{array}{l}1.528^{* * *} \\
(0.133)\end{array}$ & $\begin{array}{l}1.529^{* * *} \\
(0.133)\end{array}$ \\
\hline$g^{R O W}=\mathrm{US}$ & & $\begin{array}{l}0.507^{* * *} \\
(0.019)\end{array}$ & & & & \\
\hline$g^{R O W}=\mathrm{EA}$ & & & $\begin{array}{l}-0.596^{* * *} \\
(0.034)\end{array}$ & & & \\
\hline$g^{R O W} \_\mathrm{UK}$ & & & & $\begin{array}{l}-0.152 \\
(0.325)\end{array}$ & & \\
\hline$g^{R O W} \_\mathrm{JAP}$ & & & & & $\begin{array}{l}0.356^{* * *} \\
(0.029)\end{array}$ & \\
\hline$g^{R O W}=\mathrm{CHE}$ & & & & & & $\begin{array}{l}-0.164^{* * *} \\
(0.030)\end{array}$ \\
\hline$R^{2}$ & 0.446 & 0.446 & 0.446 & 0.446 & 0.446 & 0.446 \\
\hline$N$ & 870 & 870 & 870 & 870 & 870 & 870 \\
\hline
\end{tabular}


issuing) countries are beneficiaries of a wealth transfer when the rest of the world faces negative income shocks, as indicated by the negative coefficient of the first regressor.

To control for the size of the insurer economies, Table 14 replicates Table 13 defining the dependent variable relative to the size of the insurer's economy. On average, reserve-currency economies transfer about 0.7 percent of their own GDP in response to a 1 percent income shock in the rest of the world. Across individual reserve countries, this contribution ranges between 0.1 and 0.9 , with the US emerging again being the top insurer, closely followed by Japan and the UK, while Switzerland appears to be below average, and the EA at the bottom. Yet, this range is much narrower than the one in Table 13(before rescaling), indicating that most reserve-currency economies provide a degree of insurance broadly commensurate to the size of their individual economies.

\section{Conclusions}

The paper documents patterns of NFA dynamics for a sample of 52 economies over the period 1990-2015, within a conceptual framework that allows to analyze the different mechanisms of NFA adjustment, and specially the role of NFA financial returns.

The evidence indicates that, over the last quarter century, persistent trade imbalances have been the main driving force of diverging NFA positions, especially of systemic economies, and they have shown no sign of adjusting in response to widening stock positions. NFA returns have played an important, yet insufficient, stabilizing role. This stabilizing effect has taken place mainly through asset prices, of country's liabilities, in particular.

Our empirical evidence also points to some cross-country heterogeneity in external adjustment mechanisms. The speed of NFA adjustment is significantly higher for EMEs than for AEs, irrespective of their creditor or debtor position. Economies that issue global reserve currencies, on the other hand, adjust at a significantly slower pace than other economies.

We also find that NFA returns play an important role as insurance mechanism against domestic and global income shocks, with macro-economically meaningful magnitudes. While magnitudes vary across countries, the insurance role of NFA returns is found to be a broad phenomenon. Finally, extending previous results about the US's insurer role, we find evidence that other reserve-currency countries (Euro area, UK, Japan, Switzerland) are also providers of insurance against global income shocks in a scale broadly commensurate to the size of their economies.

each country is the sum of the three slope coefficients reported. 


\section{References}

Alberola, E., Estrada, Á., and Viani, F. (2017). Global Imbalances from a Stock Perspective. Banco de Espana Working Paper No. 1742.

Bénétrix, A. S., Lane, P. R., and Shambaugh, J. C. (2015). International Currency Exposures, Valuation Effects and the Global Financial Crisis. Journal of International Economics, 96:S98-S109.

Curcuru, S. E., Dvorak, T., and Warnock, F. E. (2008). Cross-Border Returns Differentials. The Quarterly Journal of Economics, 123(4):1495-1530.

Curcuru, S. E., Thomas, C. P., and Warnock, F. E. (2013). On Returns Differentials. Journal of International Money and Finance, 36:1-25.

Darvas, Z. and Hüttl, P. (2017). Returns on Foreign Assets and Liabilities: Exorbitant Privileges and Stabilising Adjustments. Bruegel Working Paper Issue 07.

Devereux, M. B. and Sutherland, A. (2010). Valuation Effects and the Dynamics of Net External Assets. Journal of International Economics, 80:129-143.

Forbes, K., Hjortsoe, I., and Nenova, T. (2017). Current Account Deficits During Heightened Risk: Menacing or Mitigating? The Economic Journal, 127:571-623.

Ghironi, F., Lee, J., and Rebucci, A. (2015). The Valuation Channel of External Adjustment. Journal of International Money and Finance, 57:86-114.

Gourinchas, P.-O. and Rey, H. (2007). International Financial Adjustment. Journal of Political Economy, 115(4):665-703.

Gourinchas, P.-O. and Rey, H. (2014). External Adjustment, Global Imbalances, Valuation Effect. Handbook of International Economics, 4:585-645.

Gourinchas, P.-O., Rey, H., Govillot, N., et al. (2010). Exorbitant Privilege and Exorbitant Duty.

International Monetary Fund (2016). 2016 External Sector Report.

International Monetary Fund (2017a). 2017 External Sector Report.

International Monetary Fund (2017b). Article IV Staff Report for Ireland. 
Lane, P. R. et al. (2017). The Treatment of Global Firms in National Accounts. Economic Letters Series, 2017(1).

Lane, P. R. and Milesi-Ferretti, G. M. (2009). Where Did All the Borrowing Go? A Forensic Analysis of the US External Position. Journal of the Japanese and International Economies, 23(2):177-199.

Lane, P. R. and Milesi-Ferretti, G. M. (2017). The External Wealth of Nations Mark II: Revised and Extended Estimates of Foreign Assets and Liabilities, 1970-2004. IMF Working Paper 17/115.

Nguyen, H. (2011). Valuation Effects with Transitory and Trend Productivity Shocks. Journal of International Economics, 85:245-255.

Obstfeld, M. and Rogoff, K. S. (2005). Global Current Account Imbalances and Exchange Rate Adjustments. Brookings Papers on Economic Activity, 2005:67-123.

Pavlova, A. and Rigobon, R. (2010). An Asset-pricing View of External Adjustment. Journal of International Economics, 80:144-156.

Tille, C. (2008). Composition of International Assets and the Long-run Current Account. Economic Notes, 37:283-313.

Tille, C. (2017). The Changing International Linkages of Switzerland: An Overview. Graduate Institute of International and Development Studies International Economics Department Working Paper Series, No. HEIDWP14-2017. 


\section{A Appendix: Robustness of Empirical Results}

\section{A.1 Stylized Facts}

Table 15 shows unweighted averages of different return components. The results confirm the increasingly dominant role of NFA returns, although the change over time loses its statistical significance.

Table 15: NFA Returns and Return Differentials, Unweighted

\begin{tabular}{llll}
\hline Period & $1990-2015$ & $1990-2007$ & $2008-15$ \\
\hline \hline Trade balance & 4.1 & 4.0 & 4.3 \\
Real NFA return & 6.6 & 6.3 & 7.4 \\
- Valuation change & 6.1 & 5.7 & $6.8^{*}$ \\
- Investment income & 2.6 & 2.5 & $2.9^{* *}$ \\
- Inflation & 0.8 & 0.8 & 0.7 \\
\hline Return differential & 7.5 & 8.2 & $5.9^{* *}$ \\
- Yield diff. & 2.1 & 2.0 & 2.1 \\
- Exchange rate diff. & 2.3 & 2.0 & 2.3 \\
- Asset price diff. & 7.4 & 8.4 & $5.5^{* * *}$ \\
\hline
\end{tabular}

Notes: Unweighted averages. Trade balance and NFA returns

(and its components) are reported as percent of GDP. Return

differentials (and their components) are reported as percentages.

The last row is calculated as a residual. Asterisks indicate

whether the differences across subsamples are statistically

significant at the 1,5 and 10 percent confidence levels

respectively, with standard errors clustered at the country level.

\section{A.2 NFA-Stabilizing Mechanisms}

Tables 16, 18, 19, 20, 21, 22 and 23 show that the main regression results are maintained if we respectively: i) exclude the US; ii) exclude financial centers; iii) remove GDP weights and winsorize observations with absolute changes in NFA/GDP larger than 20 percent; iv) consider 5-year lags; v) attribute BOP errors and omissions to the valuation residual; vi) use denomination in local currency instead of USD; vii) estimate with a system of seemingly unrelated regressions and viii) assume panel-corrected errors under different correlation structures. 
Table 18: NFA Dynamics and Stabilizing Components, Unweighted

\begin{tabular}{lllllllll}
\hline & $\Delta \mathrm{nfa}$ & $t b$ & $r^{N F A}$ & $g^{N F A}$ & val & $i b$ & $\pi^{N F A}$ & $r$ \\
\hline \hline L.nfa & $-0.058^{* * *}$ & 0.02 & $-0.049^{* * *}$ & -0.022 & $-0.048^{* * *}$ & $0.017^{* *}$ & $-0.019^{* * *}$ & $-0.049^{* *}$ \\
& $(0.013)$ & $(0.012)$ & $(0.012)$ & $(0.014)$ & $(0.014)$ & $(0.008)$ & $(0.001)$ & $(0.020)$ \\
$R^{2}$ & 0.085 & 0.527 & 0.187 & 0.137 & 0.128 & 0.818 & 0.906 & 0.363 \\
$N$ & 1216 & 1216 & 1216 & 1216 & 1216 & 1216 & 1216 & 1210 \\
\hline
\end{tabular}

Notes: Unweighted regression, excluding observations with $|\Delta \mathrm{nfa}|>20$ percent of GDP. Standard errors are clustered at the country level.

Table 19: NFA Dynamics and Stabilizing Components, 5-Year Lag

\begin{tabular}{lllllllll}
\hline & $\Delta \mathrm{nfa}$ & $t b$ & $r^{N F A}$ & $g^{N F A}$ & $v a l$ & $i b$ & $\pi^{N F A}$ & $r$ \\
\hline \hline L5.nfa & $-0.079^{* * *}$ & 0.016 & $-0.059^{* * *}$ & $-0.027^{* *}$ & $-0.057^{* * *}$ & 0.013 & $-0.014^{* * *}$ & $-0.072^{* * *}$ \\
& $(0.017)$ & $(0.015)$ & $(0.017)$ & $(0.013)$ & $(0.012)$ & $(0.008)$ & $(0.001)$ & $(0.021)$ \\
$R^{2}$ & 0.401 & 0.775 & 0.518 & 0.483 & 0.348 & 0.876 & 0.932 & 0.647 \\
$N$ & 1080 & 1080 & 1080 & 1080 & 1080 & 1080 & 1080 & 1073 \\
\hline
\end{tabular}

Notes: Standard errors are clustered at the country level.

Table 16: NFA Dynamics and Stabilizing Components, Excluding US

\begin{tabular}{lllllllll}
\hline & $\Delta \mathrm{nfa}$ & $t b$ & $r^{N F A}$ & $g^{N F A}$ & $v a l$ & $i b$ & $\pi^{N F A}$ & $r$ \\
\hline \hline L.nfa & $-0.071^{* * *}$ & 0.012 & $-0.060^{* * *}$ & -0.015 & $-0.068^{* * *}$ & $0.025^{* * *}$ & $-0.017^{* * *}$ & $-0.082^{* * *}$ \\
& $(0.022)$ & $(0.013)$ & $(0.019)$ & $(0.016)$ & $(0.016)$ & $(0.008)$ & $(0.001)$ & $(0.020)$ \\
$R^{2}$ & 0.069 & 0.539 & 0.119 & 0.099 & 0.079 & 0.833 & 0.901 & 0.166 \\
$N$ & 1263 & 1263 & 1263 & 1263 & 1263 & 1263 & 1263 & 1256 \\
\hline
\end{tabular}

Notes: Excluding US. Standard errors are clustered at the country level.

Table 17: NFA Dynamics and Stabilizing Components, Excluding Financial Centers

\begin{tabular}{lllllllll}
\hline & $\Delta \mathrm{nfa}$ & $t b$ & $r^{N F A}$ & $g^{N F A}$ & $v a l$ & $i b$ & $\pi^{N F A}$ & $r$ \\
\hline \hline L.nfa & $-0.070^{* * *}$ & 0.018 & $-0.074^{* * *}$ & 0.000 & $-0.082^{* * *}$ & $0.024^{* *}$ & $-0.016^{* * *}$ & $-0.109^{* * *}$ \\
& $(0.023)$ & $(0.019)$ & $(0.020)$ & $(0.013)$ & $(0.016)$ & $(0.012)$ & $(0.001)$ & $(0.019)$ \\
$R^{2}$ & 0.079 & 0.603 & 0.116 & 0.075 & 0.081 & 0.800 & 0.899 & 0.207 \\
$N$ & 1188 & 1188 & 1188 & 1188 & 1188 & 1188 & 1188 & 1188 \\
\hline
\end{tabular}

Notes: Excluding economies with average gross assets and liabilities above ten times GDP (Ireland, Hong Kong SAR, Singapore and Netherlands). Standard errors are clustered at the country level. 
Table 20: NFA Dynamics and Stabilizing Components, BOP E\&Os

\begin{tabular}{|c|c|c|}
\hline & $r^{N F A}$ & val \\
\hline L.nfa & $\begin{array}{l}-0.072^{* * *} \\
(0.020)\end{array}$ & $\begin{array}{l}-0.090^{* * *} \\
(0.015)\end{array}$ \\
\hline$R^{2}$ & 0.143 & 0.108 \\
\hline$N$ & 1288 & 1288 \\
\hline
\end{tabular}

Table 21: NFA Dynamics and Stabilizing Components, Local-Currency

\begin{tabular}{lcccc}
\hline & $r^{N F A}$ & val & $\pi^{N F A}$ & $r$ \\
\hline \hline L.nfa & $-0.057^{* *}$ & $-0.060^{* * *}$ & $-0.015^{* * *}$ & $-0.091^{* *}$ \\
& $(0.024)$ & $(0.018)$ & $(0.004)$ & $(0.044)$ \\
$R^{2}$ & 0.117 & 0.083 & 0.4 & 0.089 \\
$N$ & 1277 & 1288 & 1277 & 1281 \\
\hline \multicolumn{4}{l}{ Notes: Variables are denominated in local currency (instead } \\
of USD). Standard errors are clustered at the country level.
\end{tabular}

Table 22: NFA Dynamics and Stabilizing Components, SUR

\begin{tabular}{lllll}
\hline & $\Delta \mathrm{nfa}$ & $t b$ & $r^{N F A}$ & $g^{N F A}$ \\
\hline \hline L.nfa & $-0.064^{* * *}$ & $0.015^{* * *}$ & $-0.065^{* * *}$ & $-0.014^{* *}$ \\
& $(0.013)$ & $(0.004)$ & $(0.012)$ & $(0.006)$ \\
$R^{2}$ & 0.07 & 0.65 & 0.13 & 0.10 \\
$N$ & 1288 & 1288 & 1288 & 1288 \\
\hline
\end{tabular}

Notes: We impose that the coefficient on $\Delta \mathrm{nfa}$ is equal to the sum of the coefficients on the trade balance, the NFA return and the growth component. 
Table 23: NFA Dynamics and Stabilizing Components, Panel-Corrected S.E.

\begin{tabular}{llllllllll}
\hline & I. & \multicolumn{9}{c}{ II. } & \multicolumn{1}{c}{ III. } \\
\hline & $\Delta$ nfa & $t b$ & $r^{N F A}$ & $\Delta$ nfa & $t b$ & $r^{N F A}$ & $\Delta$ nfa & $t b$ & $r^{N F A}$ \\
\hline \hline L.nfa & $-0.062^{* * *}$ & 0.006 & $-0.069^{* * *}$ & $-0.059^{* * *}$ & 0.003 & $-0.064^{* * *}$ & $-0.062^{* *}$ & 0.006 & $-0.069^{* *}$ \\
& $(0.022)$ & $(0.007)$ & $(0.022)$ & $(0.022)$ & $(0.006)$ & $(0.022)$ & $(0.030)$ & $(0.009)$ & $(0.029)$ \\
$R^{2}$ & 0.075 & 0.319 & 0.123 & 0.077 & 0.331 & 0.134 & 0.075 & 0.319 & 0.123 \\
$N$ & 1288 & 1288 & 1288 & 1288 & 1288 & 1288 & 1288 & 1288 & 1288 \\
\hline
\end{tabular}

Notes: The first three columns assume AR(1) errors, uncorrelated across countries and with a common autocorrelation coefficient. Columns 6-8 allow for heterogeneous autocorrelation coefficients across countries. The last three columns allow for contemporaneous correlation across countries, with a common autocorrelation coefficient. 